\title{
A new, systematic approach to determine the global energy optimum of a hybrid vehicle
}

\author{
Andreas Lange ${ }^{1} \cdot$ Ferit Küçükay $^{1}$
}

Received: 3 December 2015/Accepted: 12 September 2016/Published online: 22 September 2016

(c) Springer International Publishing Switzerland 2016

\begin{abstract}
Hybridization is one of the key technologies to reduce the fuel consumption of a vehicle with internal combustion engine (ICE) significantly. Using at least one electric motor (EM), the kinetic energy of the vehicle can be recuperated and the ICE can operate more efficiently. The control strategy (CS) coordinates the torque of the ICE and the EM. If the driving cycle is known, the coordination of the drive units can be adjusted for every point in time, therefore the fuel consumption based on the entire cycle is minimal. Dynamic programming, for example, can be used, but computation time is long and it offers only a few degrees of freedom to evaluate the potential of hybrid drives. For this reason, a new method to identify the global energy optimum in a particularly systematic and transparent way was developed at the Institute of Automotive Engineering. It is therefore a globally optimal control strategy. At the same time, the approach is efficient in terms of computation time and inherently SOC neutral, therefore allowing a very good comparability of results.
\end{abstract}

Keywords Control strategy · Global optimum · Hybrid drive $\cdot$ Efficiency $\cdot$ Consumption $\cdot$ Energy

Andreas Lange

an.lange@tu-braunschweig.de

Ferit Küçükay

iffzg@tu-braunschweig.de

1 Institute of Automotive Engineering, Brunswick, TU, Germany

\section{Introduction}

A key objective in the development of a control strategy is to maximize the efficiency of the powertrain to generate the best benefit from hybridization for the customer. For this purpose, the global energy optimum is a theoretical value, which represents the potential of the powertrain and the control strategy. The global energy optimum is, therefore, also a suitable basis for comparison with different powertrain concepts. Current methods, however, require a lot of computation time, so extensive parameter studies can hardly be carried out. Dynamic programming (DP) for example will provide a reliable globally optimal solution but needs approximately hundred to thousand times more computation time than the equivalent consumption minimization strategy (ECMS) [1-3]. This can be seen in Table 1.

Although the ECMS leads to very good fuel consumption, it will not provide a theoretical energy optimum. Instead, it does enable relatively short simulation durations which are important for case studies or online optimization of a vehicles' control strategy. The new globally optimal control strategy presented in this paper was developed to achieve simulation times on the same level as the ECMS [4-6].

In addition, the results of known strategies like DP or the ECMS often evade the intuition so they are difficult to understand and lack transparency. As a consequence, it can be very difficult to figure out the reasons for efficiency advantages or disadvantages for different hybrid concepts. The approach presented in this paper determines the global energy optimum gradually and systematically within multiple steps. Therefore, the powertrain can be evaluated in terms of pure mechanical efficiency (no use of the battery), recuperation, pure electric driving and the sensitivity and 
Table 1 Control strategy comparison regarding memory and calculation effort [1]

\begin{tabular}{llll}
\hline Control Strategy & Memory effort & Calculation effort & Calculation time (s) \\
\hline ECMS & 1 & $N_{\mathrm{OP}}$ & $1 / 40$ \\
DP & $t_{\text {pred }} \cdot N_{\mathrm{OP}}$ & $t_{\text {pred. }} \cdot N_{\mathrm{OP}}^{2}$ & 60 \\
\hline
\end{tabular}

$N_{O P}$ number of possible operation point combinations, $t_{\text {pred }}$ predicted horizon (time steps)

${ }^{a}$ MATLAB simulation with Intel Core i7-3520M efficiency regarding load point shift. This makes the new strategy demonstrative and, at the same time, efficient in terms of computational time.

\section{Basics}

The results presented in this paper are based on a compact car with a parallel hybrid drive system ( $\mathrm{P} 2$ topology). The parameters of the hybrid electric vehicle (HEV) and the powertrain are given in Table 2.

The powertrain consists of a $120 \mathrm{~kW}$ internal combustion engine (ICE), an $80 \mathrm{~kW}$ electric machine (EM), and a 7 -speed dual clutch transmission (DCT). The vehicle mass includes the mass of the powertrain. Compared to a conventional vehicle, an additional mass of $150 \mathrm{~kg}$ was considered for electrification. Stationary maps are used to represent the efficiency of energy as well as torque and speed converters. Since efficiency maps can cause numerical inaccuracy during interpolation especially at low loads, absolute losses were used to calculate energy consumption.

The simulation model is quasi-stationary which means that dynamic effects (e.g., turbo lag) are not considered. Additionally, the battery is assumed to have unlimited capacity. Its efficiency depends on the battery power but dependencies to the state of charge (SOC) are neglected. Since the influence of the SOC on the battery efficiency is usually very small in a relatively wide SOC range, this assumption can be made without sacrificing too much accuracy. Furthermore, no criteria of drivability, comfort or $\mathrm{NVH}$ are considered [7].

To evaluate the fuel consumption for an HEV properly, SOC neutrality is important. The presented control strategy is inherent SOC neutral therefore no parameter iterations are needed which also saves computation time. Nevertheless, a blended charge sustaining operation (for Plug-In

Table 2 Parameters of the P2 hybrid vehicle
$\mathrm{HEV}$ ) is also possible if a certain $\triangle \mathrm{SOC}$ will be defined as a constraint.

The functionality of the globally optimal control strategy (GOCS) is explained at first based on the NEDC because the synthetic speed profile makes it easier to understand. The principals of the GOCS apply to each and every driving cycle. In this respect, a boost functionality is not implemented yet, but will be in the future. For the presented driving cycles in this paper boosting is not relevant though. After explaining the functionality in NEDC, customer use will be investigated with the GOCS.

\section{Global optimum without auxiliary consumers}

Figure 1 shows the input and output parameters of the GOCS. Before applying the control strategy, all possible operation point combinations need to be calculated for each and every time step of a known driving cycle. This effort is equivalent to the ECMS. Usually this makes up for the major computation time depending on the potential for load point shift. The GOCS chooses the best operation points according to the procedure, which will be explained in the following. The basic outputs of the strategy are time discrete values for the drive units. Moreover, it provides a detailed energetic evaluation of the powertrain, which addresses the claimed transparency in the introduction.

For a first description and explanation of the hybrid drive, it is not appropriate to take the power demand of the auxiliaries into account. They will therefore not be considered in the following but later on.

\subsection{Conventional ICE operation (battery neutral operation)}

The driving cycle is completed first with ICE only. For this reason, the battery is not used to accelerate or decelerate the vehicle. If the EM cannot be disconnected from the drivetrain, which is the case for the presented P2 hybrid, occurring drag losses are taken into account.

The only degree of freedom for a control strategy in this case is the selection of an appropriate gear of the dual clutch transmission at any point in the cycle. They are set with regard to optimum efficiency to achieve the best possible consumption for conventional ICE operation. The ICE will be switched off at standstill (stop-start operation). 
Fig. 1 Input and output of the GOCS
Simulation model

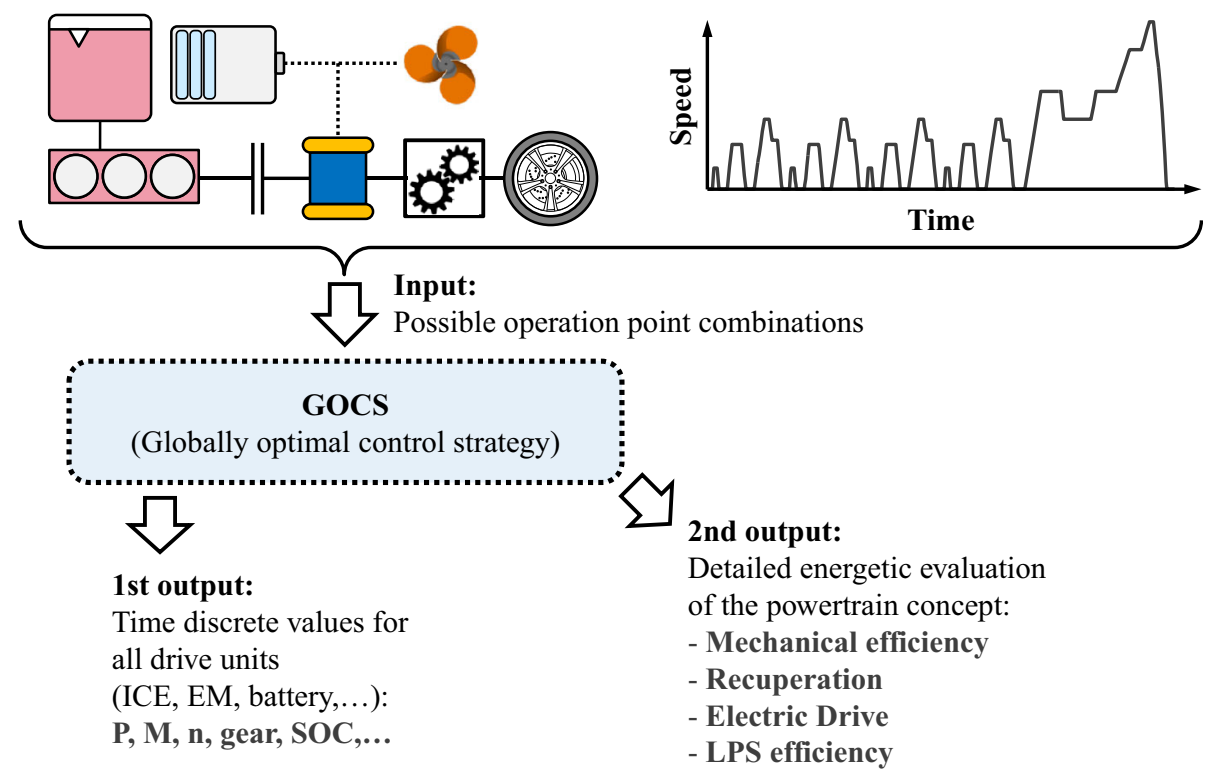

Fig. 2 ICE operation without using the battery (ICE op) is illustrated by the red areas. Power from the fuel tank $\left(P_{\text {Tank }}\right)$ is minimized for each time step. $P_{\text {Tank }}$ is equivalent to fuel mass flow. Battery power $\left(P_{\mathrm{Bat}}\right)$ is zero

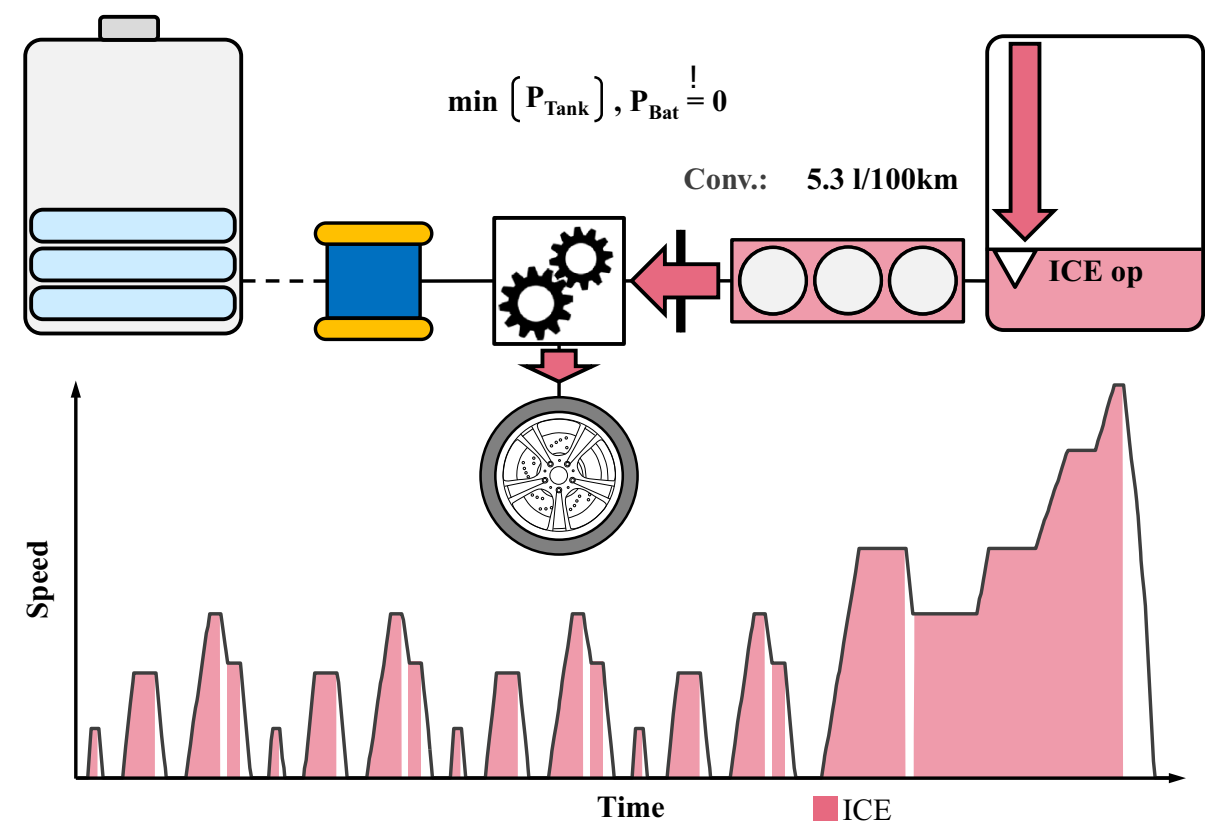

Basically, the control strategy chooses the operation points by minimizing fuel tank power $\left(P_{\text {tank }}\right)$ for each and every time step. Based on the above-mentioned vehicle parameters, it results in a consumption of 5.3 1/100 km. In Fig. 2, the phases in which the ICE is driving can be identified as the red areas. In the thrust phase it is dragged or disabled. Thus, there is no consumption (white areas).

\subsection{Recuperation}

The perhaps most important feature of a hybrid system is recuperation. The kinetic energy of the vehicle is recuperated in the form of electric energy by the EM operating as a generator as the vehicle decelerates. Recuperation is always useful in the thrust phases since the use of the mechanical brake at points when recuperation was still possible would mean an increase in the total losses. The control strategy presented in this paper does not take any battery limits into account. It is assumed that the battery can store any amount of energy. If the maximum generator power of the EM for a certain deceleration is insufficient, the mechanical brakes are used to achieve the required deceleration. The recuperation power is also limited by the traction limit. Recuperation limitations 
through practical brake balances are neglected. With this respect, the control strategy can achieve the theoretical recuperation optimum. As a result of the recuperation, the battery SOC increases (see Fig. 3). The ICE is turned off during recuperation and decoupled from the powertrain to avoid drag losses if possible. In general, the control strategy chooses the operation point with the highest battery charging power where the ICE is turned off completely (or dragged if needed).

The recuperated energy is now available to the powertrain again. To maximize its efficiency, the electric energy is used to achieve the greatest fuel savings. This is the case where the ratio of electric energy and fuel consumption is minimal. Basically, the electric energy can be deployed to decrease the engine load or to disable the engine and drive electrically. For the presented vehicle in the NEDC, the highest fuel savings are achieved through electric driving. The operating points with the lowest powertrain efficiency (engine and transmission combined) are replaced and the gear selection for electric operation is also carried out with optimum efficiency. In contrast to heuristic operation strategies, there is no static threshold for electric driving like [8] has described. Instead the presented control strategy optimizes the fuel saving for a given amount of electrical energy.

Due to recuperation, considerable parts of the NEDC can already be covered in electric mode. This is illustrated in Fig. 4: the fuel consumption drops from 5.3 to $3.8 \mathrm{l} /$ $100 \mathrm{~km}(-28 \%)$. Since the presented control strategy makes it possible to quantify the potential of recuperation based on an optimal ICE operation, it is also possible to compare the presented powertrain to other hybrid concepts specifically regarding recuperation and electric driving efficiency (transparency).

\subsection{Recuperation and electric driving as driving resistance}

Driving resistance can also be used to illustrate the effect of combining the operating modes "recuperation" and "electric driving". Figure 5 shows the driving resistance energies for the above-mentioned vehicle for both the traction and the thrust phase in the NEDC. In theory, the acceleration resistance of the traction phase minus the irreversible driving resistances of the thrust phase can be recovered. The efficiency of energy conversion, however, has to be taken into account so that about $60 \%$ of the theoretically recoverable energy is available again at the wheel. Thus, the driving resistance of the traction phase can be reduced, resulting in a driving resistance reduced by recuperation. In addition to a reduction of the driving resistances, the average efficiency of the ICE is increased since operating points in low efficiency ranges are now driven electrically [9].

\subsection{Load point shift (LPS)}

In addition to recuperation and the related electric driving, the efficiency of the powertrain can be further improved under certain constraints by applying the LPS concept. For this purpose, more load decreasing or electric driving points are added and ICE operating points with the lowest powertrain efficiency are replaced. Thus, losses from previous ICE operation are reduced by discharging the battery.
Fig. 3 Recuperation in NEDC. Battery power $\left(P_{\mathrm{Bat}}\right)$ is minimized for each time step during the thrust phases $\left(P_{\mathrm{Bat}}<0\right.$ : charging). ICE is disconnected from the drivetrain and turned off $\left(P_{\text {Tank }}=0\right)$. Fuel consumption is equal to ICE op (ICE operation)

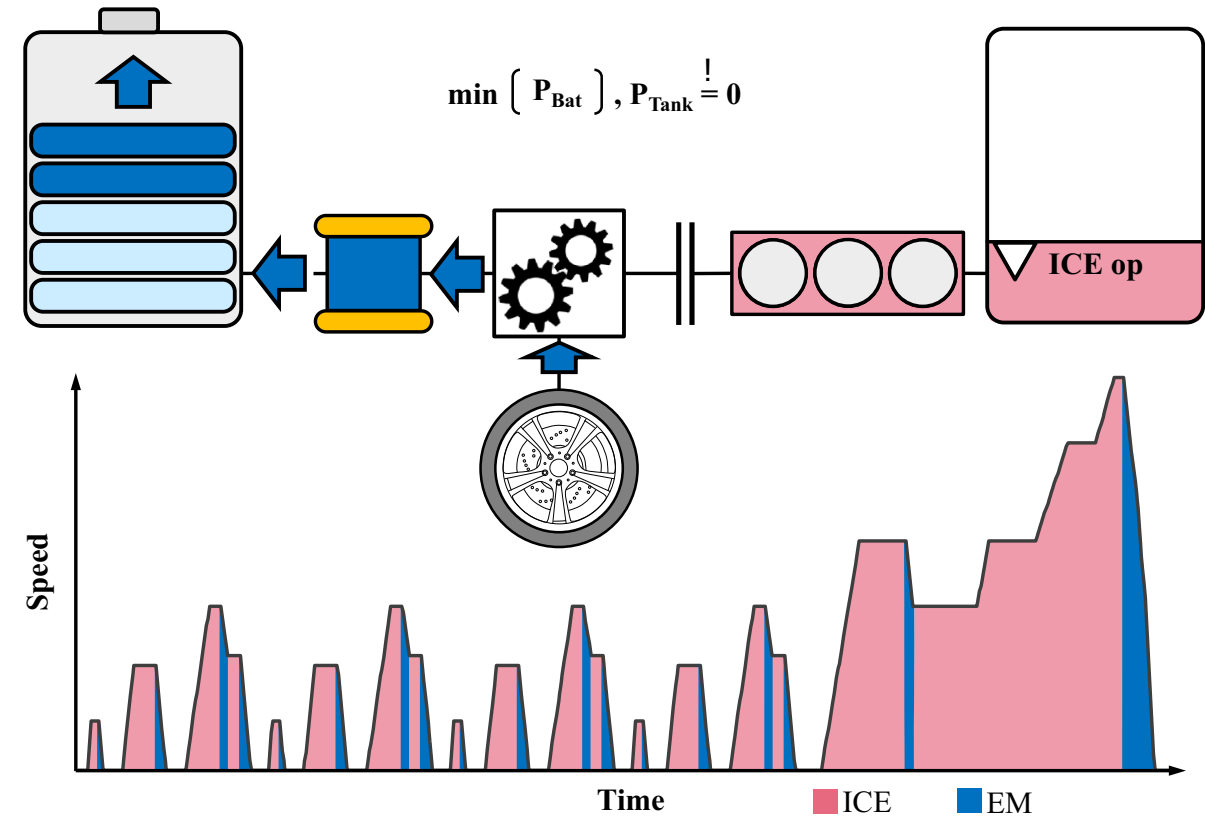


Fig. 4 Electric driving due to recuperation. Absolute ratio of additional battery power $\left(\Delta P_{\text {Bat }}\right)$ and reduced tank power $\left(\Delta P_{\text {Tank }}\right)$ is minimized. Battery is discharged $\left(\Delta P_{\mathrm{Bat}}>0\right)$. Fuel consumption decreases from ICE op (ICE operation) to $\mathrm{Rec}+\mathrm{ED}$ (recuperation and electric driving)

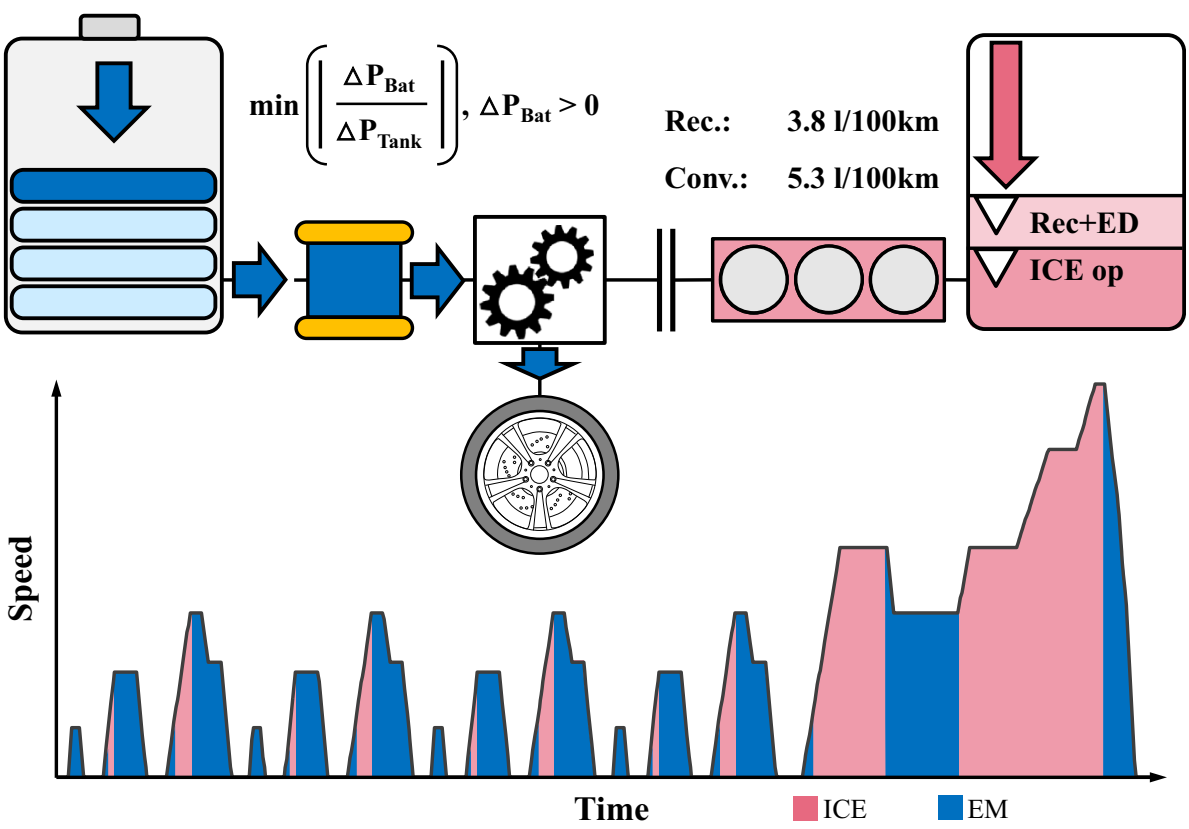

Fig. 5 Relation between driving resistances, recuperation, and electric driving. Energy demand through driving resistances $\left(E_{\mathrm{DR}}\right)$ is $11.5 \mathrm{kWh} / 100 \mathrm{~km}$ during traction phase. Recuperation potential (RP) is $18 \%$. ICE efficiency increases from $28 \%$ (without recuperation) to $31 \%$ (with recuperation)

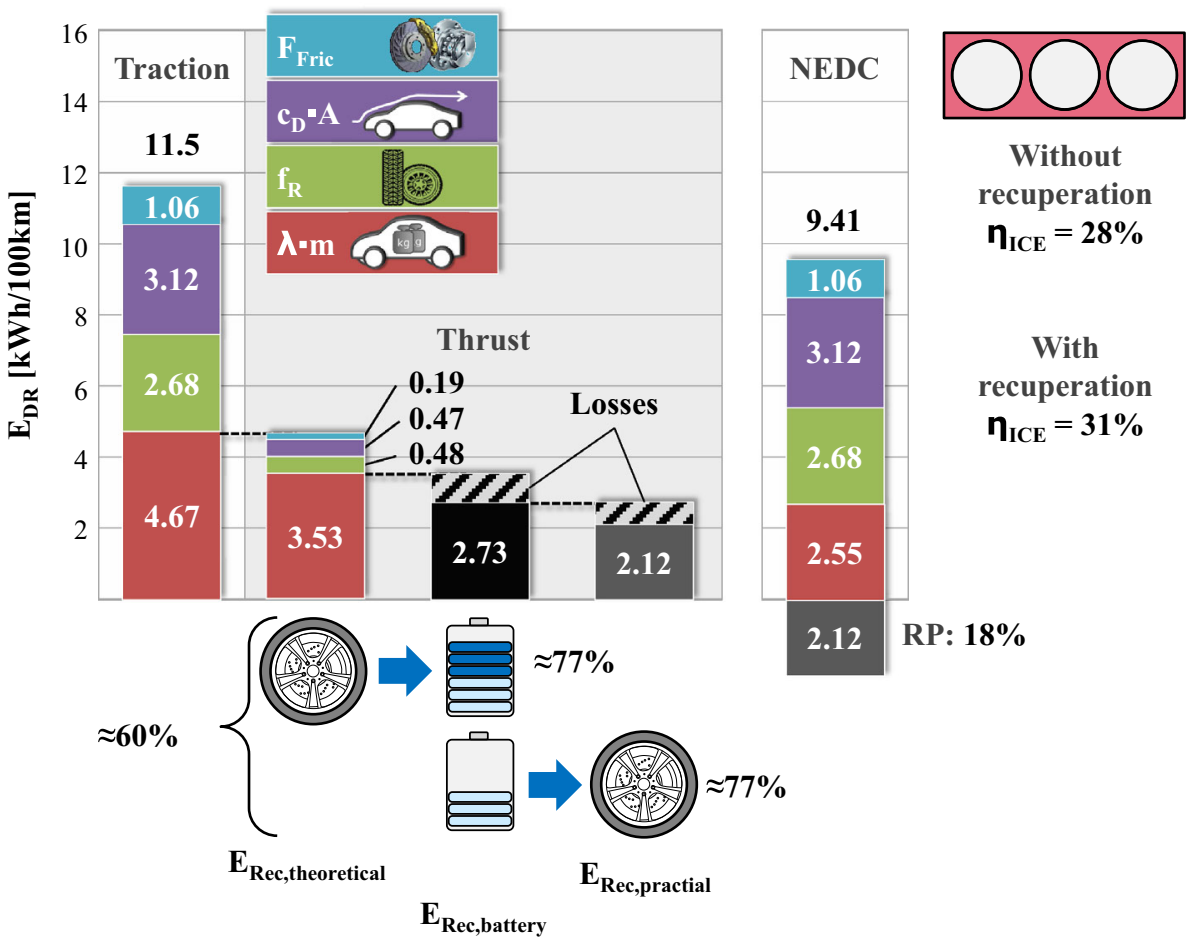

This, however, results in new losses in the conversion chain of the LPS because the electric energy needs to be recharged by the ICE at another time step. These LPS losses have to be compared to the previous losses in conventional ICE operation. The replacement of ICE operation by LPS and electric driving is useful if the energy losses of LPS are lower than those of ICE operation (Fig. 6).

To minimize the losses of LPS operation, the electric energy for the additional electrical operating points has to be recharged in an optimal way. For this purpose, all time steps are taken into account where the ICE is still active. All torque combinations for all gears of ICE and EM are considered for each operation point. The control strategy calculates the ratio of battery charging power and fuel tank power for each possible operation point. The point with the maximum of recharged electric energy in relation to additional fuel consumption is selected. This ensures that the necessary recharging is associated with minimal 
Fig. 6 Loss analysis of load point shift (LPS). LPS and electric driving is beneficial if losses during LPS procedure $\left(E_{\mathrm{L}, \mathrm{LPS}}\right)$ are lower than losses in ICE operation $\left(E_{\mathrm{L}, \mathrm{ICE} \text { op }}\right)$

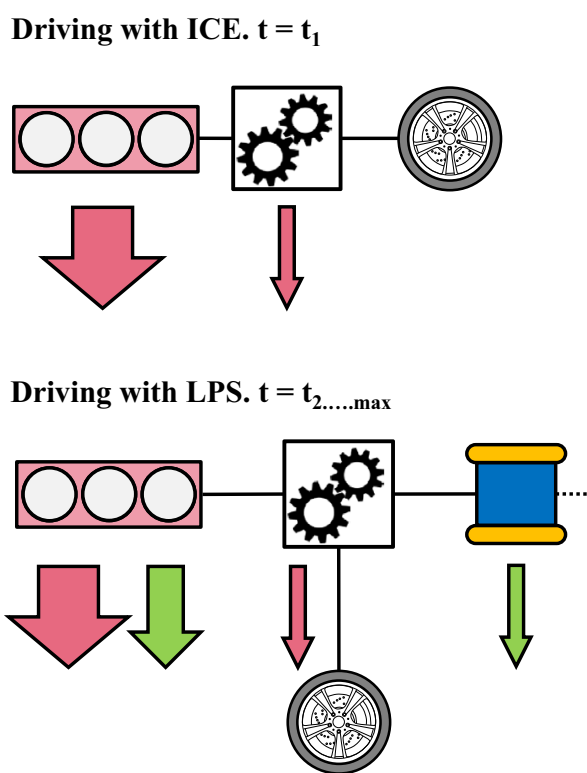

additional consumption. SOC neutrality is also ensured because the engine does only recharge the electrical energy needed for electric driving or load decrease applied beforehand.

The control strategy is capable of calculating different levels of LPS. Therefore, it is possible to investigate the influence of different LPS levels on the fuel consumption. However, to determine the global energy optimum, the optimal amount of additional electric driving and LPS needs to be optimized. This can be done by iteration or by choosing the minimal fuel consumption after calculating LPS levels continuously. The full LPS procedure (discharging and recharging) is illustrated in Figs. 7 and 8. The present vehicle and cycle example shows that electric driving can result in a further reduction in fuel consumption for the constant $70 \mathrm{~km} / \mathrm{h}$ phases. Most of the optimal recharging is achieved in a range between 70 and $120 \mathrm{~km} /$ h. Due to electric driving as a result of LPS, the consumption can be reduced by another $3 \%$ to $3.71 / 100 \mathrm{~km}$.

\subsection{LPS and electric driving as driving resistance}

Similar to the previous analysis of recuperation, driving resistance can also be used to illustrate the effect of combining the hybrid modes "LPS" and "electric driving" (Fig. 9). Based on the driving resistance reduced through recuperation, the driving resistance could be further reduced by additional electric driving in the traction phase. The electric power, however, has to be generated by ICE and EM. The additional losses arising from the energy conversion chain "generator-battery-battery-motor" could be clearly interpreted as an increase in driving resistance. On the other hand, there is an increase in powertrain efficiency, so an optimal compromise between driving resistance and efficiency increase is achieved in the end. LPS is useful in this process as long as the relative increase in efficiency exceeds the relative increase in driving resistance.

\section{Consideration of auxiliary consumers}

In the previous approach, the auxiliary consumers were not taken into account to make their consideration in the following more plausible. Without taking them into account, the recuperated energy was directly used for electric driving. Additional electric driving due to the LPS further improved the efficiency.

Nevertheless, electric auxiliary consumers require additional electrical energy from the battery. Now, it would be an obvious idea to recharge the battery afterwards by LPS. However, this is not correct methodically. If it is assumed that the energy demand of the auxiliary units exactly corresponds to the recuperated energy, the causality can be changed in the way that the recuperated energy is used for the auxiliaries and additional LPS for electric driving (Fig. 10). However, this does not make sense since electric driving due to LPS does not always result in an increase in efficiency. Depending on the driving cycle and the vehicle, it is possible that a reduction in fuel consumption cannot be achieved using LPS and electric driving. For this reason, electric driving through recuperation cannot be taken for granted from the outset. Instead, the auxiliaries have to be powered through recuperation at first; if there is excess recuperated energy, it can be used for electric driving. If the recuperated energy is not sufficient for the auxiliaries, the required electric power has to be generated by ICE and EM. Only then it can be checked 
Fig. 7 Electric driving through LPS. Battery is discharged $\left(\Delta P_{\text {Bat }}>0\right)$. Fuel consumption is optimized by minimizing the absolute ratio of additional battery power $\left(\Delta P_{\text {Bat }}\right)$ and reduced tank power $\left(\Delta P_{\text {Tank }}\right)$. Fuel consumption is decreased temporarily compared to ICE operation (ICE op) and electric driving through recuperation $(\mathrm{Rec}+\mathrm{ED})$ because of additional electric driving (Add ED) without recharging the battery

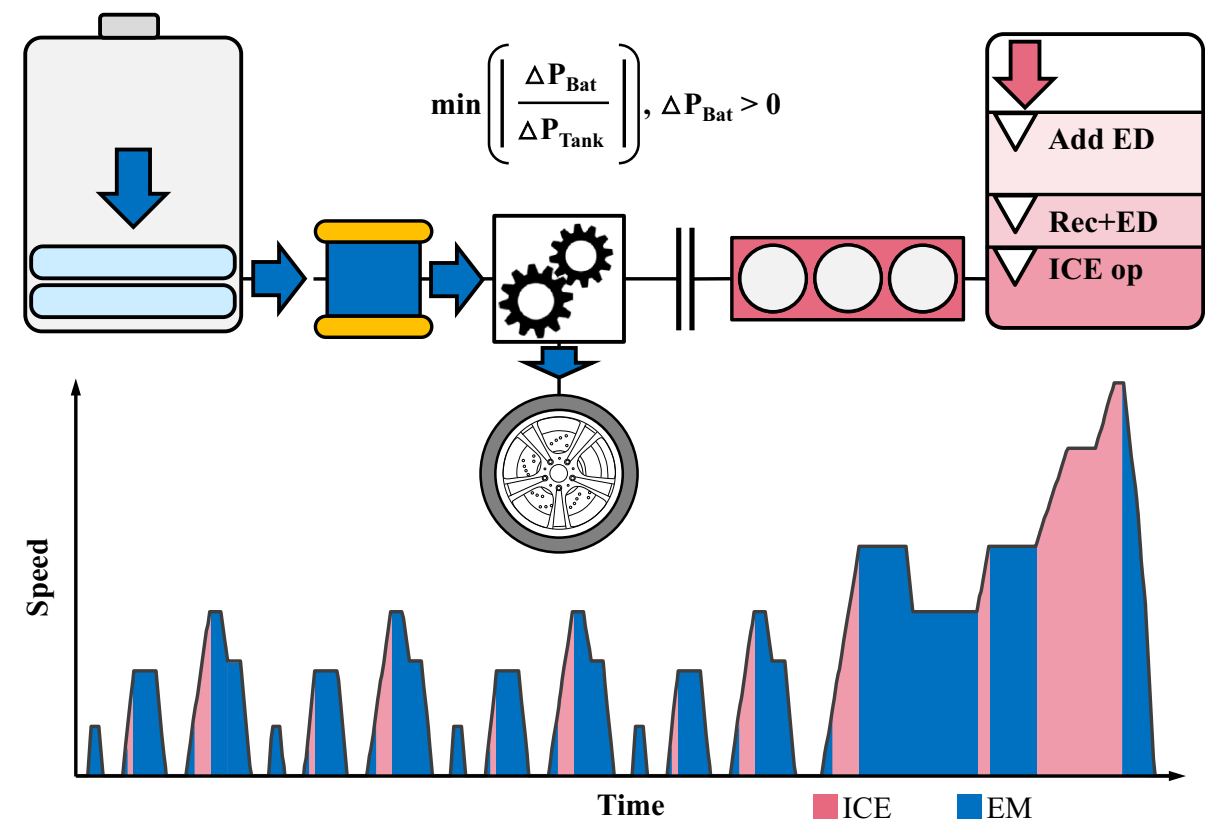

Fig. 8 Recharging the battery through LPS. Battery is recharged $\left(\Delta P_{\text {Bat }}<0\right)$ to the initial state (SOC neutrality) by maximizing the absolute ratio of battery charging power $\left(\Delta P_{\mathrm{Bat}}\right)$ and increased tank power $\left(\Delta P_{\text {Tank }}\right)$. Therefore, fuel consumption increases compared to previous phase (dotted gray line). Electric driving and LPS (ED + LPS) still provide better fuel consumption than recuperation and electric driving $(\mathrm{Rev}+\mathrm{ED})$ or ICE operation (ICE op)

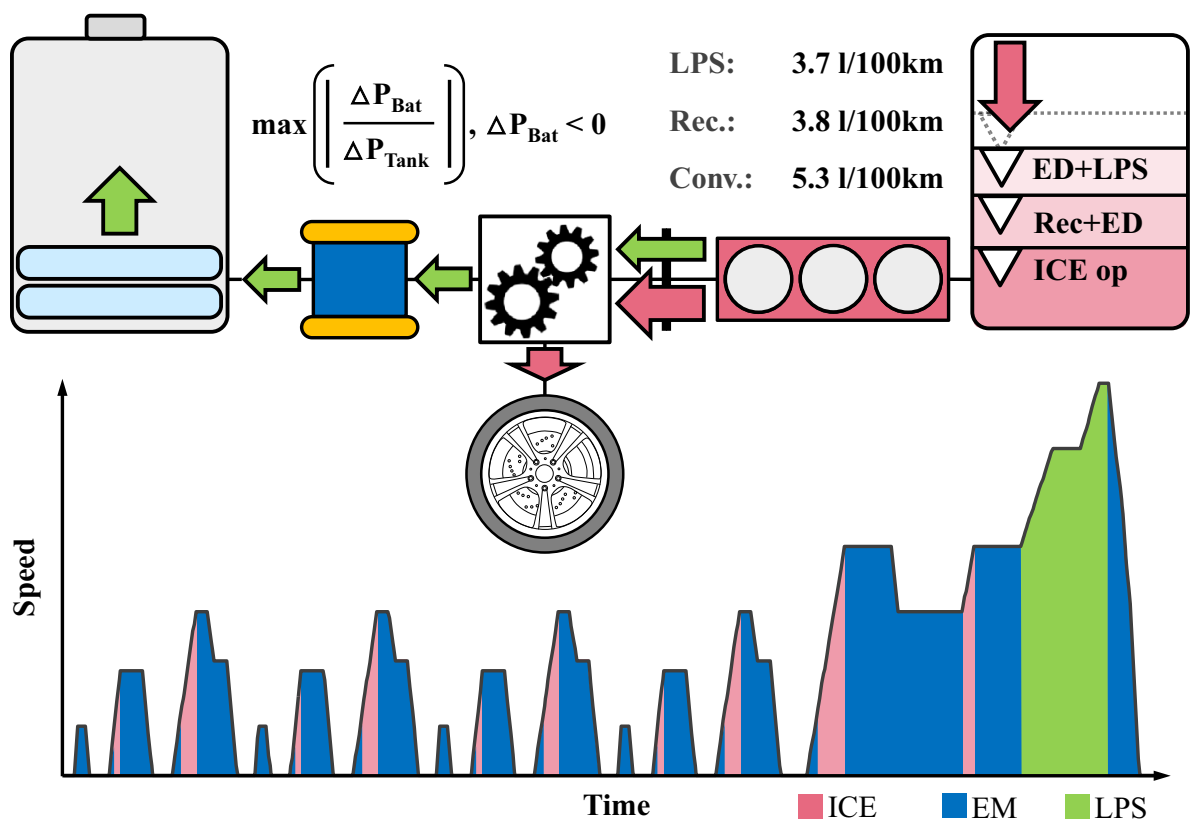

whether the energy efficiency of the powertrain can be further optimized by LPS and electric driving.

The generation of electric energy for powering the auxiliaries also has to be done in an optimal way. It has to be taken into account that the energy demand of the auxiliaries depends on whether they are supplied by EM (directly) or battery (indirectly). Thus, the tank energy demand for supplying the auxiliary consumers is compared in a specified operating point to assess whether direct or indirect supply is more efficient. For this purpose, the operating point is selected where the ratio of electric power and additional tank power is maximized (similar to LPS). The whole GOCS approach is shown in Fig. 11.

\section{Optimal control strategy in costumer use}

To assess the behavior of the control strategy, customer cycles were considered in addition to the NEDC. The cycles were generated using the 3D method developed at the Institute of Automotive Engineering, which allows a representative illustration of the customer use for specified 


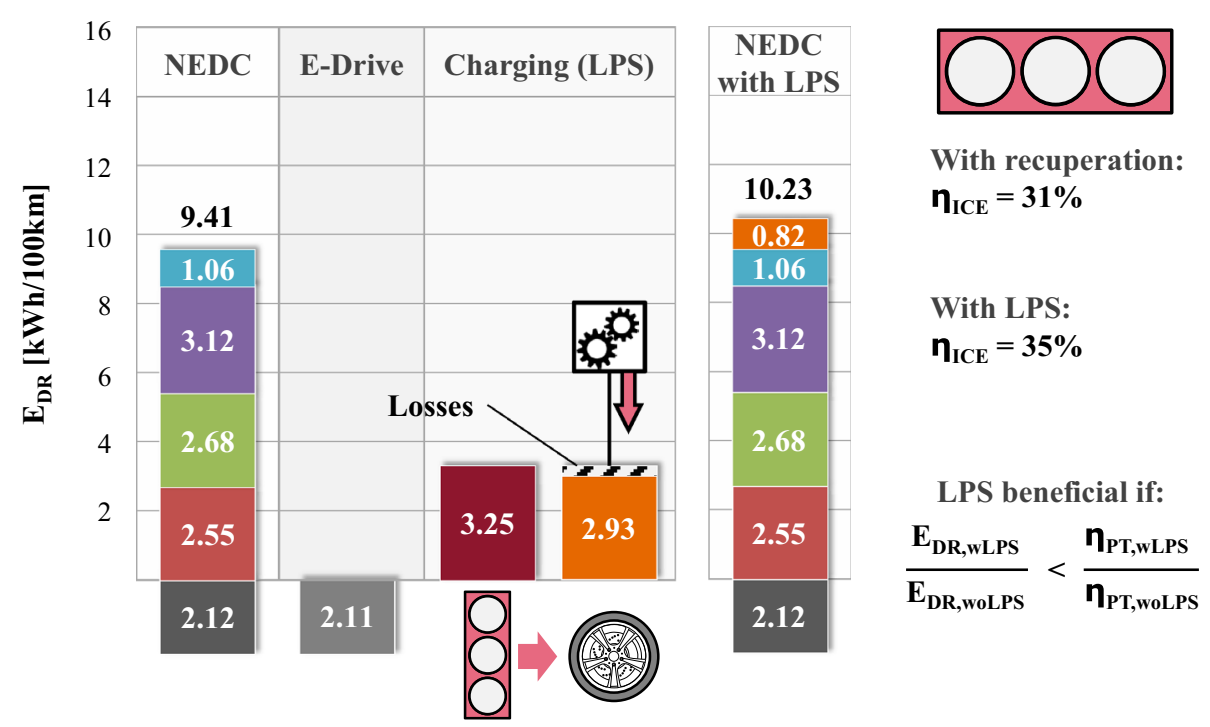

Fig. 9 Relation between driving resistances, LPS, and electric driving. Efficiency of the chain "ICE-battery-wheel" is assumed with $65 \%$. Transmission efficiency is assumed with $90 \%$. Due to LPS losses, the energy demand through driving resistances $\left(E_{\mathrm{DR}}\right)$ increases by $0.82 \mathrm{kWh} / 100 \mathrm{~km}$. However, the average engine efficiency increases from $31 \%$ (electric driving through recuperation) to $35 \%$ (additional electric driving through LPS). LPS and electric driving are beneficial if the increase in energy demand through driving resistances ( $E_{\mathrm{DR} \text {,wLPS }}$ : driving resistance energy demand with

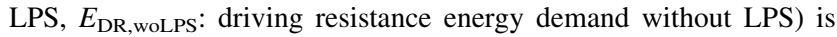
smaller than the increase in powertrain efficiency $\left(\eta_{\mathrm{PT}, \mathrm{wLPS}}\right.$ : Powertrain efficiency with LPS, $\eta_{\mathrm{PT}, \text { woLPS }}$ : Powertrain efficiency without LPS)
Fig. 10 Simplified energy balance for the hybrid battery

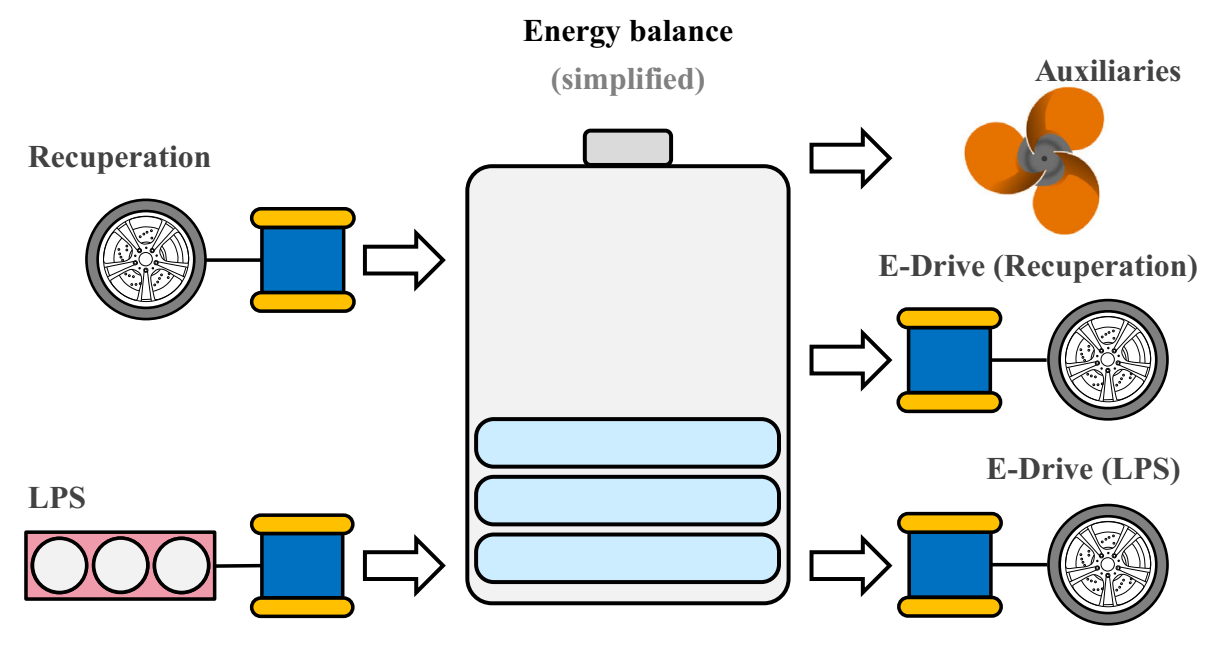

Auxiliary energy demand must be prioritized and supplied through recuperation E-Drive afterwards (through Recuperation or LPS) driver, driving environment and vehicle profiles. Representative city cycles for mild, average, and sporty drivers were generated. The time curves and selected cycle parameters are shown in Fig. 12. It is immediately apparent that the effective speeds as well as the average accelerations increase with an increasingly sporty driving style. Furthermore, the number of acceleration processes increase with a sportier driving style since the percentage of thrust phases in relation to the total distance rises. The frequency of speed changes therefore increases $[10,11]$.
It is obvious based on the driving resistances presented in Fig. 13 that the acceleration resistance dominates in all driving cycles; the percentage further increases with a sportier driving style. Thus, the highest recuperation potential occurs with the sporty urban driver. While the energy demand in the traction phase increases by $22 \%$ for the average and $55 \%$ for the sporty driver (based on a mild driver), the driving resistance reduced by recuperation is only increased by $13 \%$ (average) and $33 \%$ (sporty). 
Fig. 11 GOCS approach. 1 ICE operation. 2 Recuperation. 3 If electric energy remains in the battery after supplying the auxiliaries, load decrease or electric driving will follow. Otherwise, the battery needs to be recharged through the ICE. 4 Additional load decrease or electric driving. 5 Recharging the battery through load point shift (LPS) of the engine

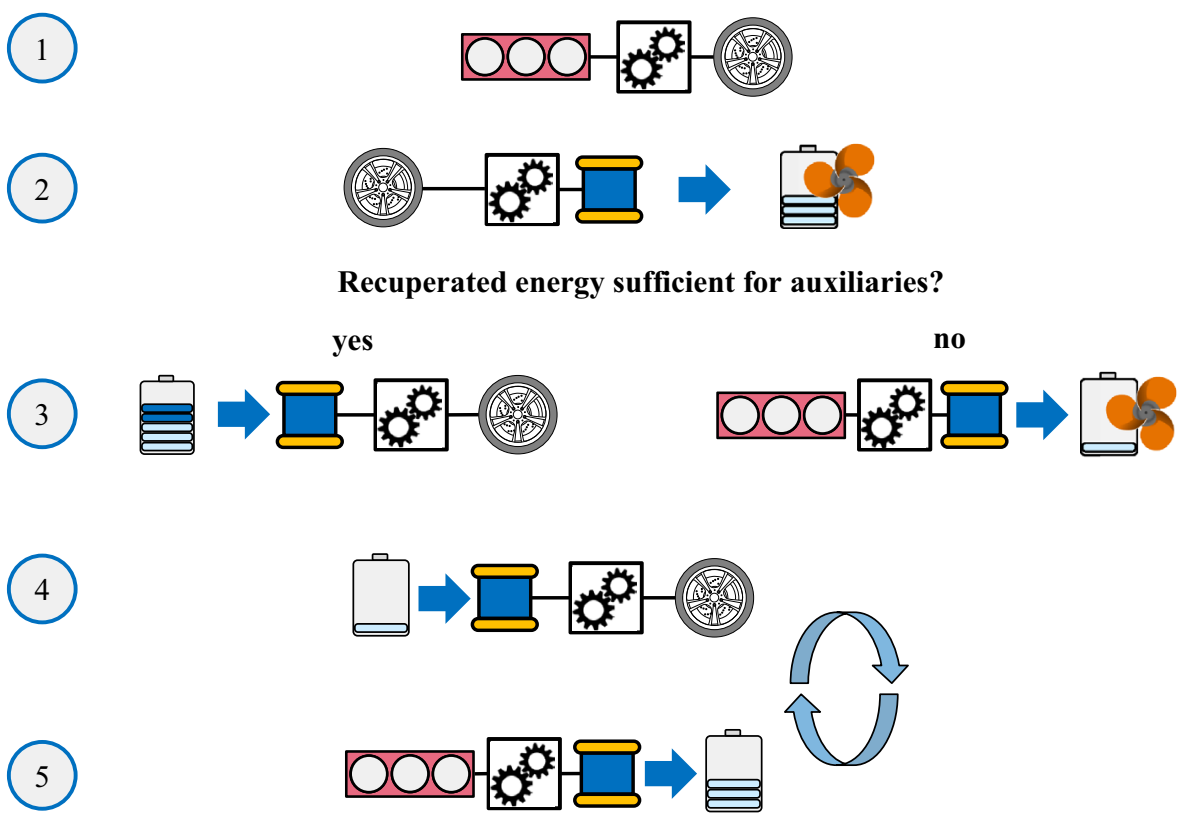

Fig. 12 Cycle-related parameters of 3D city cycles
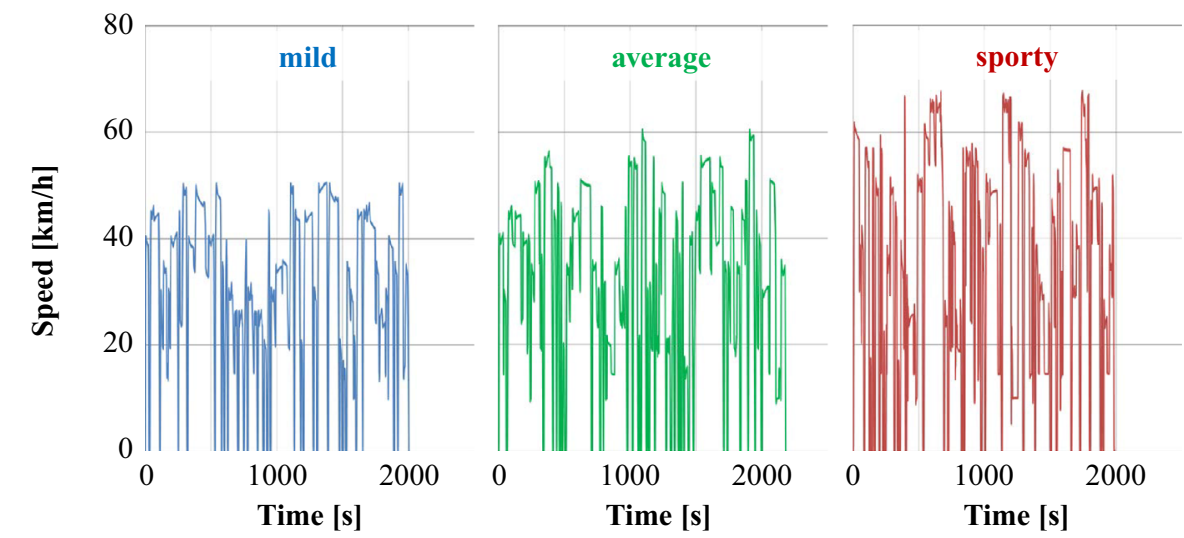

\begin{tabular}{|c|c|c|c|c|c|c|}
\cline { 2 - 7 } \multicolumn{1}{c|}{} & Traction & Thrust & Traction & Thrust & Traction & Thrust \\
\hline $\mathbf{s} / \mathbf{s}_{\text {total }}$ & 0.85 & 0.15 & 0.84 & 0.16 & 0.78 & 0.22 \\
\hline $\begin{array}{c}\mathbf{v}_{\text {eff }} \\
{[\mathrm{km} / \mathrm{h}]}\end{array}$ & 40 & 33 & 44 & 38 & 51 & 45 \\
\hline $\begin{array}{c}\mathbf{a}_{\text {average }} \\
{\left[\mathrm{m} / \mathrm{s}^{2}\right]}\end{array}$ & 0.15 & -0.81 & 0.21 & -1.07 & 0.32 & -1.15 \\
\hline
\end{tabular}

The previously explained relations between the hybrid modes and the driving resistances are used to illustrate the results. Using the mild driver as an example, the GOCS method is discussed again (Fig. 14), based on a conventional vehicle with optimum gear selection and stop-start system. If the vehicle can recuperate and supply the power to the auxiliaries, the consumption can already be reduced by about $5 \%$ without affecting the driving resistance. If the remaining recuperated energy is used for electric driving, the driving resistance is significantly reduced on the one hand and on the other the efficiency of the ICE is increased. The fuel consumption is therefore reduced by approx.
$33 \%$. Thus, additional electric driving is possible; the required recharging through the ICE results in an increase of the driving resistance. A point with the optimum ratio of efficiency and driving resistance increase can be identified; this is where the optimal consumption is achieved. For a mild driver, the LPS can result in a fuel consumption improved by about $6 \%$.

The same analysis was also done for the other types of drivers (Fig. 15). It can be seen that the efficiency potential of hybridization increases with a sporty driving style. This is particularly due to the higher recuperation potential since the percentage of dynamic driving maneuvers increases. 
Fig. 13 Energy demand through driving resistance $\left(E_{\mathrm{DR}}\right)$ of 3D city cycles. Power demand of auxiliaries $\left(P_{\text {aux }}\right)$ is assumed with $200 \mathrm{~W}$ (board net). Recuperation efficiency for auxiliary supply ("wheel to auxiliary") is assumed with $75 \%$. Recuperation efficiency of the chain "wheel-batterywheel" is assumed with $60 \%$. The recuperation potential (RP) increases with a sportier driving style from 21 to $33 \%$.

Nevertheless, total energy demand of driving resistances increases from 7.84 to $10.4 \mathrm{kWh} / 100 \mathrm{~km}(+33 \%)$

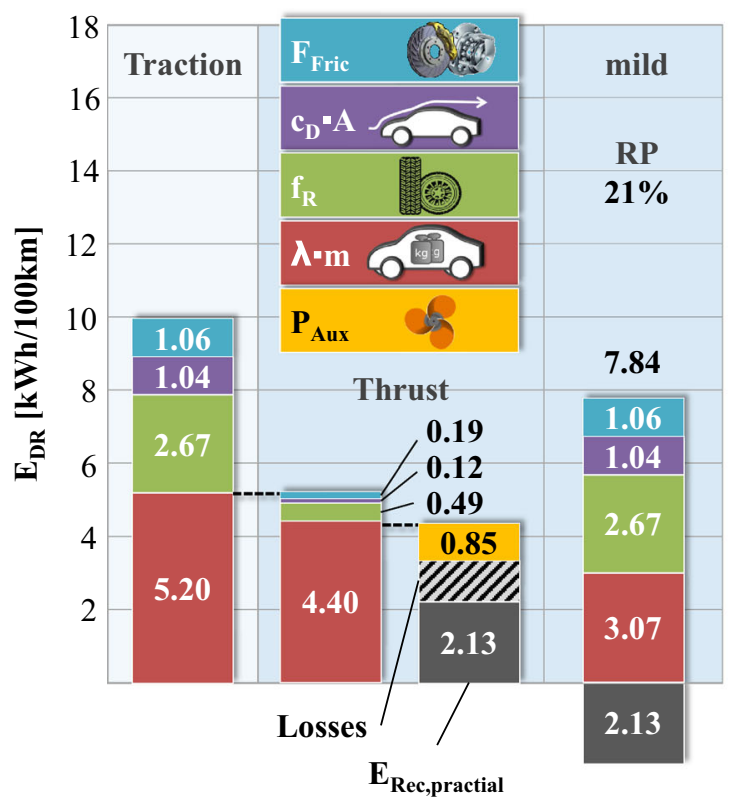

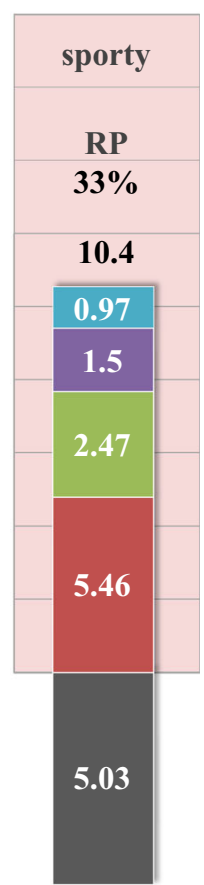

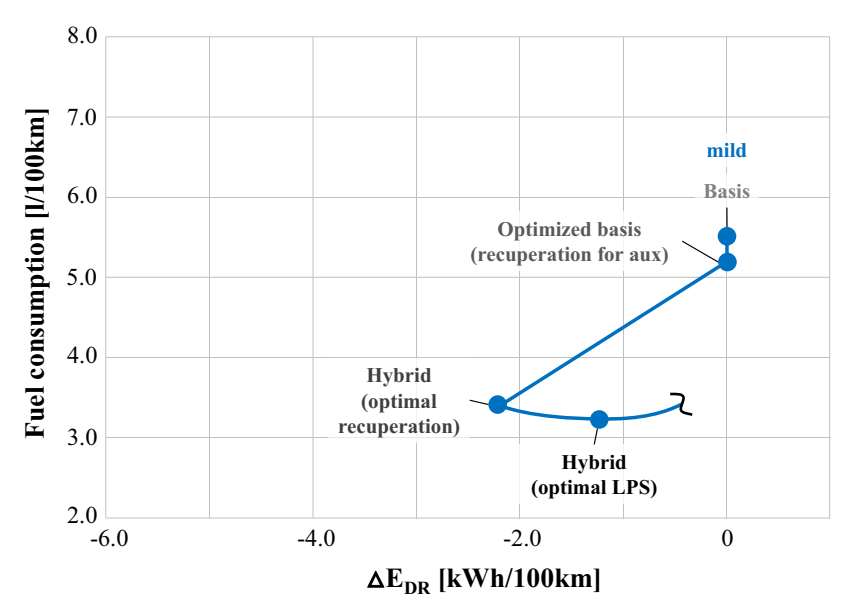

Fig. 14 Impact of hybrid modes on driving resistance $\left(\Delta E_{\mathrm{DR}}\right)$ and fuel consumption for a mild urban driver. If no hybrid functionalities are being used, a fuel consumption of $5.51 / 100 \mathrm{~km}$ will be achieved (ICE operation). If recuperation is used to supply the energy demand of the board net (auxiliaries), fuel consumption does decrease by approx. $5 \%$. Remaining energy from recuperation can be used to lower the energy demand through driving resistances and increase the powertrain efficiency. Therefore, fuel consumption decreases by approx. $33 \%$. Moreover, several levels of load point shift (LPS) can be applied (curved line). An optimum can be identified where fuel consumption is improved by about $6 \%$ despite increasing the driving resistance by approx. $1 \mathrm{kWh} / 100 \mathrm{~km}$

The high dynamics additionally lead to high engine loads with correspondingly high ICE efficiencies; the combination of LPS and electric driving therefore does not increase the powertrain efficiency and even reduces the fuel economy. The more sensible the driving, the higher are the fuel

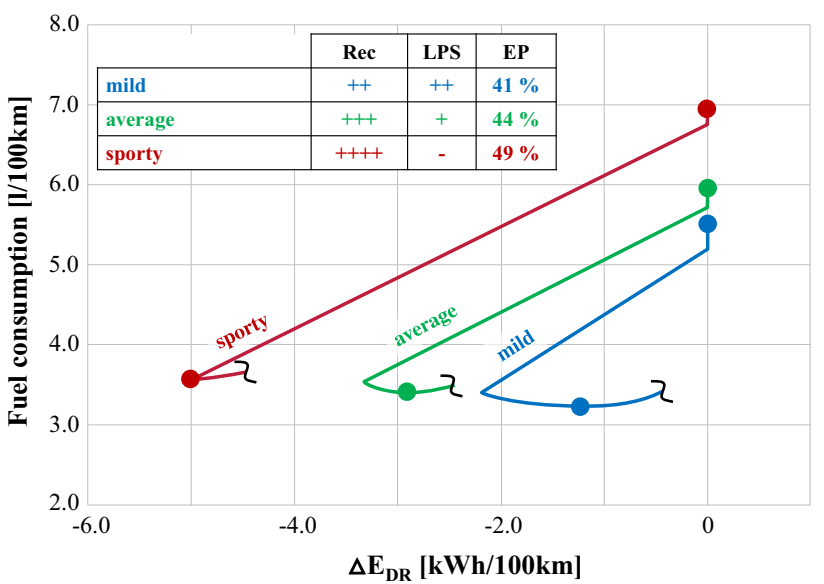

Fig. 15 Impact of hybrid modes on driving resistance $\left(\Delta E_{\mathrm{DR}}\right)$ and fuel consumption for a mild, average, and sporty urban driver. The electrification potential (EP) increases with a sportier driving style in an urban environment because recuperation also increases with a sportier driving style. However, the potential of load point shift (LPS) and electric driving decreases with a sportier driving style

savings due to LPS. Looking at the lines reveals that the minimum consumption of the mild driver is in a comparatively broad LPS range, so the solution can be described as robust in terms of LPS intensity. For the average driver, however, LPS can result in reduced fuel consumption, but the LPS range is rather narrow. Thus, the solution is less robust in case of suboptimal LPS levels.

Table 3 lists the minimum power of the ICE with and without LPS. It can be seen that LPS increases the minimum performance for mild and average drivers 
Table 3 Lower ICE power limits in 3D city cycles with and without load point shift (LPS)

\begin{tabular}{lcc}
\hline & $P_{\text {ICE,min,without LPS }}(\mathrm{kW})$ & $P_{\text {ICE,min,with LPS }}(\mathrm{kW})$ \\
\hline Mild & 2.8 & 8.4 \\
Average & 3.9 & 9.3 \\
Sporty & 20.6 & 20.6 \\
\hline
\end{tabular}

considerably. For a sporty driver, LPS cannot increase the powertrain efficiency since the remaining operating points-after recuperation and electric driving-already correspond to very high performance that cannot be increased any further. It also has to be remarked that the differences between mild and average driving style are quite small compared to the differences between average and sporty driver. It can be derived that a control strategy needs to adapt to different driving styles. Due to the high recuperation potential and the strong accelerations of the sporty driver, the control strategy needs to enable electric driving at relatively high power. As a result, LPS should be disabled for the sporty city driver.

Figure 16 represents the SOC lines of the three different types of drivers. It can be seen that the GOCS provides a SOC neutral operation. Since the cycles are statistically generated, the lines cannot be compared. It can, however, be deduced what kind of battery capacity is required for the respective types of drivers to complete the driving cycle in an optimal way. It can be noted that the required battery capacity of $0.3 \mathrm{kWh}$ for the average driver is comparatively small. The considered scenario therefore does not require a battery with high energy capacity to achieve optimal fuel economy. The minimum battery capacity for the mild driver is similar, $0.28 \mathrm{kWh}$, while the sporty driver requires only $0.23 \mathrm{kWh}$. Again, that depends strongly on the speed profile. Another reason for the relatively small required battery capacity when driving sporty is the disabled LPS. The total recuperation may be the highest but is compensated through electric driving throughout the entire driving cycle.

\section{Summary}

In this paper, a new approach to systematically determine the global energy optimum of a hybrid electric vehicle was introduced. The method can be used to gradually identify the potential of different hybrid modes. It allows a particularly transparent analysis of the consumption behavior of a hybrid concept. Compared to other methods, the approach is also very efficient in terms of computing time and can therefore also be used for parameter studies of hybrid vehicles. The systematic approach with regard to the

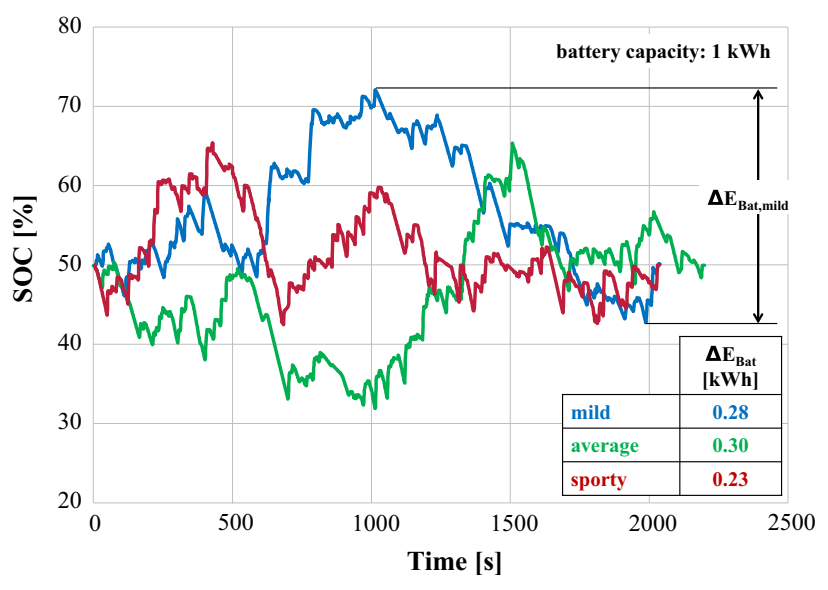

Fig. 16 SOC trends for a mild, average, and sporty driver. The difference between maximum and minimum SOC equals the minimum battery capacitiy which is needed to achieve the best fuel consumption

use of the different hybrid modes was described and explained based on the NEDC. Furthermore, the potential of the hybrid modes recuperation and LPS was quantified and illustrated with reference to driving resistances. It was shown that reducing the fuel consumption of hybrid vehicles is based on a combination of reduction of driving resistance and increase in efficiency. The developed control strategy was then applied to three different types of drivers in an urban driving environment according to the 3D method. The results revealed that the operation range of the engine and the electric motor is quite different if an optimum result has to be achieved. A limitation compared to other methods currently is the fact that battery SOC limits are not taken into account. It can, however, be deduced from the results what battery size would be optimal. In case of the considered city cycles, a battery with comparatively low energy capacity is sufficient.

\section{Outlook}

A parallel hybrid with P2 topology was used to illustrate the approach to determine the global energy optimum presented in this paper. Since the approach is based on fundamental energetic considerations, it can also be extended to systems with several EM and different powertrain topologies. Additionally, the boost functionality will be implemented for cases where ICE power alone is not sufficient. Furthermore, it is possible to take constraints into account, e.g., specific phases of a driving cycle that require electric driving. This, for instance, could be zero emission zones in cities. Particularly in view of real vehicle use, the question arises how the driving cycle can be predicted to calculate the energy optimum. This could be done 
using the 3D method in combination with the driving style identifier developed at the Institute of Automotive Engineering. Using the driving style identifier and taking a number of parameters into account, the driving style of the driver can be determined while driving (mild, average or sporty). The present driving environment and the slope profile can be determined using navigation data. Together with the driving style it results in a representative speed profile, which can be used as a constraint for the optimization of the control strategy. When the driving cycle is known, the presented operation strategy can be used to adapt the operation strategy parameters of the vehicle. Therefore, the results are analyzed and parameters are derived out of these to tune the implemented control strategy of the vehicle. For instance, for a sporty city driver the implemented operation strategy parameters can be modified to realize electric driving at higher loads without recharging the battery through LPS too much [12-14].

\section{References}

1. Wang, J.: Rekursiv vorausschauende Betriebsstrategie für parallele Hybridfahrzeuge. Prof. Dr. Hermann Koch-Gröber, Hochschule Heilbronn, 13. Braunschweiger Symposium: Hybrid- und Elektrofahrzeuge (2016)

2. Serrao, L.: A comparative analysis of energy management strategies for hybrid electric vehicles. Center for Automotive Research, The Ohio State University. J. Dyn. Syst. Meas. Control. 133, 031012-1-031012-9 (2011)

3. Back, M.: Prädiktive Antriebsregelung zum energieoptimalen Betrieb von Hybridfahrzeugen. Dissertation, Universität Karlsruhe (TH) (2005)
4. Sciarretta, A., Black, M., Guzzella, L.: Optimal control of parallel hybrid electric vehicles. IEEE Trans. Control Syst. Technol. 12, 3 (2004)

5. Yuan, Z., Teng, L., Fengchun, S., Peng, H.: Comparative study of dynamic programming and Pontryagin's Minimum Principle on energy management for a parallel hybrid electric vehicle. Energies 6, 2305-2318 (2013)

6. Kim, N., Cha, S., Peng, H.: Optimal control of hybrid electric vehicles based on Pontryagin's Minimum Principe. IEEE Trans. Control Syst. Technol. 19, 1279-1287 (2011)

7. Zhang, P., Du, C., Yan, F., Kang, J.: Research on energy efficiency of the vehicle's battery pack. Electric Information and Control Engineering (ICEICE) (2011)

8. Mapelli, F., Mauri, M., Tarsitano, D.: Energy control strategies comparison for a city car Plug-In HEV. Industrial Electronics, 35th Annual Conference of IEEE (2009)

9. Küçükay, F.: Effiziente Fahrzeugantriebe-Grenzen und Potentiale. Plenary speech, 10. MTZ Fachtagung "Der Antrieb von morgen", Wolfsburg (2015)

10. Müller-Kose, J.P.: Repräsentative Lastkollektive für Fahrzeuggetriebe. Dissertation, TU Braunschweig, Institut für Fahrzeugtechnik, Shaker Verlag (2002)

11. Eghtessad, M.: Optimale Antriebsstrangkonfigurationen für Elektrofahrzeuge. Dissertation, TU Braunschweig, Institut für Fahrzeugtechnik, Shaker Verlag (2014)

12. Boßdorf-Zimmer, J., Kollmer, H., Henze R., Küçükay, F.: Fingerprint des Fahrers zur Adaption von Assistenzsystemen. ATZ 03/11, pp. 226-231. Springer, Heidelberg (2011)

13. Henze, R., Kollmer, H., Pion, O., Küçükay, F.: Adaptation of ADAS-functions by monitoring driver characteristics. FAST-zero 2011, Tokyo, Japan (2011)

14. Pion, O.: Bestimmung des Fahrerleistungsvermögens zur Adaption von Fahrerassistenzsystemen. Dissertation, TU Braunschweig, Institut für Fahrzeugtechnik, Shaker Verlag (2015) 